\title{
Waist hip ratio in early pregnancy as a clinical indicator of serum lipid levels and predictor of pregnancy complications
}

\author{
Divya Khare, Jyoti Nath Modi*
}

Department of Obstetrics and Gynaecology, People's college of Medical Sciences and Research Centre, Bhopal, India

Received: 25 April 2016

Accepted: 05 May 2016

\section{*Correspondence: \\ Dr.Jyoti Nath Modi, \\ E-mail: modijn@gmail.com}

Copyright: () the author(s), publisher and licensee Medip Academy. This is an open-access article distributed under the terms of the Creative Commons Attribution Non-Commercial License, which permits unrestricted non-commercial use, distribution, and reproduction in any medium, provided the original work is properly cited.

\begin{abstract}
Background: Deranged lipid profile has been associated with pregnancy complications such as gestational hypertension. The waist hip ratio (WHR) is one of the measures of body fat distribution. This research work aims to study whether WHR in early pregnancy correlates with serum lipid levels so as to serve as a clinical indicator of dyslipidemia, and as a predictor of pregnancy complications.

Methods: As a part of a larger ongoing cohort study, interim data analysis was carried out for the 120 antenatal women recruited in early pregnancy (upto 16 weeks). At the first antenatal visit WHR, body mass index (BMI) and serum lipid profile including lipid risk ratios were measured and clinical information recorded. The women were followed through pregnancy till delivery and antenatal complications noted. The cut-off for WHR was taken at 0.80 as per Indian guidelines.

Results: Of the 120 pregnant women, $94(78 \%)$ had WHR $>0.80$ and 26 women had WHR $\leq 0.80$. The mean BMI of women in the first group (WHR >0.80) was significantly higher than that of the second group. However, the mean levels of each of the lipid components and the risk ratios were not significantly different between the two groups. Overall $(\mathrm{N}=120)$, the WHR showed weak positive correlation only with very low density lipoprotein (VLDL) serum levels. The group of women with WHR $>0.80$ had a higher rate of developing gestational hypertension. The babies born to these mothers also had a higher rate $(5.3 \%)$ of admission to neonatal intensive care unit (NICU).

Conclusions: The waist hip ratio in early pregnancy has the potential to serve as a clinical indicator of lipid levels. It can also be explored as a predictor of pregnancy complications such as gestational hypertension in larger cohort studies.
\end{abstract}

Keywords: Waist hip ratio, Early pregnancy, Pregnancy complications, Body mass index, Lipid profile

\section{INTRODUCTION}

Waist hip ratio (WHR) is one of the measures of body fat distribution besides the body mass index (BMI), waist circumference (WC) and skin fold thickness. ${ }^{1}$ The ratio provides a measure of both subcutaneous and intraabdominal adipose tissue. Earlier studies have demonstrated that the WHR is a better predictor of morbidities such as myocardial infarction, stroke and also of premature death, than the BMI among men. Among women too, the WHR is a stronger independent risk factor for these conditions than the BMI. ${ }^{1,2}$ The WHR has been reported to correlate with the serum lipid levels to a variable degree in women. ${ }^{2-4}$ Further, dyslipidaemia has been found to be associated with pregnancy complications such as gestational hypertension (GH), pre-eclampsia and fetal macrosomia. ${ }^{5-7}$

In resource limited setting as ours it may not be possible to measure pre-pregnancy or early pregnancy serum lipids as a routine, but WHR can serve as a surrogate marker or clinical indicator for lipid profile. Though pre- 
pregnancy WHR would be ideal for screening and prediction, it may be more feasible to measure early pregnancy WHR in our settings since a majority of pregnant women do not visit a health care facility until late first trimester. Some studies have reported that waist circumference upto 16 weeks of gestation can predict pregnancy induced hypertension and preeclampsia., Measuring WHR could also form a part of pre-pregnancy counselling for raising awareness about appropriate weight prior to conception.

The present research work studies the correlation of WHR in early pregnancy with serum levels of individual lipid components and risk ratios so as to identify the bestcorrelated lipid. Further, it aims to explore the WHR as a possible predictor of pregnancy complications.

\section{METHODS}

The present research work is carried out as a part of a larger ongoing cohort study on serum lipid levels in early pregnancy and pregnancy outcome. Interim data analysis was carried out for the 120 antenatal women recruited in early pregnancy for the above study. The pregnant women upto 16 weeks of gestation, attending the antenatal care clinic, or admitted in the obstetrics ward of People's hospital, Bhopal, India (affiliate teaching hospital of People's college of medical sciences and research centre, Bhopal, India) were included, between January 2014 and December 2014 (12 months), after taking written informed consent. The women who were unwilling to participate in the study and those with diabetes mellitus, hypertension, cardiac disease, familial dyslipidemias, or hypothyroidism were excluded. The study was initiated after approval from the institutional ethics committee.

At the first antenatal visit, a detailed history and examination was done and clinical information recorded. The height, weight, waist and hip circumference were measured and noted for calculating the BMI and WHR. At this time, the serum lipid profile including the lipid ratios were measured besides the routine antenatal investigations.

The height and weight was recorded without footwear to the nearest $0.1 \mathrm{~cm}$ and $0.1 \mathrm{Kg}$ respectively. The waist circumference (WC) was measured at the midpoint between lower margin of the last palpable rib and the top of the iliac crest using a flexible non-stretchable plastic measuring tape to the nearest $0.1 \mathrm{~cm}$. The hip circumference (HC) was measured at the largest circumference of the hip using the same measuring tape. The cutoff for WHR was taken at 0.80 as per Indian guidelines. ${ }^{1,2}$

The lipid components measured were high density lipoprotein (HDL), low density lipoprotein (LDL), very low density lipoprotein (VLDL), triglycerides (TG) and total cholesterol (TC). The risk ratios calculated were
TG/LDL and TC/HDL. A blood sample after overnight fast (8-10 hours) was drawn for the purpose and lipid components measured in serum by an automatic analyzer.

The women were followed through pregnancy till delivery and antenatal complications noted.

\section{Statistical analysis}

Descriptive statistics (Mean, Standard deviation (SD), minimum and maximum values (Range))was used to describe parameters such as age, BMI, WHR for whole group. Data was grouped by WHR as WHR $\leq 0.80$ and $>0.80$ and analyzed. The Shapiro-Wilk test showed that age, BMI, lipid components and risk factor ratios for the whole group did not follow normal distribution curve. Hence, non-parametric tests were used for further data analysis.

For comparison of age, BMI, lipid components and risk factor ratios between the groups with WHR $\leq 0.80$ and $>0.80$ respectively, Mann Whitney $U$ test was used. The correlation of WHR with BMI, lipid components and risk factor ratios was evaluated using Spearman's rank order correlation. The P-values $<0.05$ were accepted as statistically significant. All analysis was performed using version 21.0 of the Statistical Package for Social Sciences (IBM Corporation, Armonk, New York, USA).

\section{RESULTS}

The data was analysed for a total of 120 pregnant women recruited in early pregnancy and followed till delivery. The mean age of the women in the whole group was 25.1 years (range 19-39 years; SD 3.75). Of the 120 women, $94(78 \%)$ women had WHR $>0.80$ in early pregnancy and 26 had WHR $\leq 0.80$. Overall, the mean WHR for the whole study group was 0.83 (range $0.75-0.87$; SD 0.03 ). A comparative analysis of group of women with WHR $\leq 0.80\left(\mathrm{n}_{1}=26\right)$ and WHR $>0.80\left(\mathrm{n}_{2}=94\right)$, was done and also correlation was studied between WHR and serum lipid levels. The mean age of women in the two groups was not significantly different (Mann Whitney $U$ test statistic (MW) 1063.55; $\mathrm{P}=0.311$ ) as shown in Table 1.

\section{BMI}

The mean BMI for the whole study group was 20.69 $\mathrm{Kg} / \mathrm{m}^{2}$ (range $18-25 \mathrm{Kg} / \mathrm{m}^{2}$; SD \pm 1.64 ). The mean BMI of the group of women with WHR $>0.80$ was significantly higher than the women with WHR $\leq 0.80$ as shown in Table 1 ( $\mathrm{MW}=805 ; \mathrm{P}=0.0008)$. The mean $\mathrm{BMI}$ of both the subgroups however was in the normal range for Indian population. Only twelve out of 94 women with WHR $>0.80$ were obese $\left(\mathrm{BMI}>23 \mathrm{Kg} / \mathrm{m}^{2}\right)$. In the subgroup with normal WHR $(\leq 0.80)$, one woman out of 26 was obese $(3.8 \%)$. 
Table 1: Mean age and BMI of the whole study group $(\mathrm{N}=120)$, and comparison between WHR subgroups (WHR >0.80 versus $W H R \leq 0.80)$.

\begin{tabular}{|c|c|c|c|c|c|c|c|}
\hline \multirow[t]{2}{*}{ Variable } & \multicolumn{2}{|c|}{$\begin{array}{l}\text { Whole study group } \\
(\mathrm{N}=120)\end{array}$} & \multicolumn{2}{|c|}{$\begin{array}{l}\text { Subgroup WHR } \leq 0.80 \\
\left(\mathbf{n}_{1}=26\right)\end{array}$} & \multicolumn{2}{|c|}{$\begin{array}{l}\text { Subgroup WHR }>0.80 \\
\left(\mathrm{n}_{2}=94\right)\end{array}$} & \multirow{2}{*}{$\begin{array}{l}\text { Mann whitney U test } \\
\text { for comparison }\end{array}$} \\
\hline & Mean & Range (SD) & Mean & Range (SD) & Mean & Range (SD) & \\
\hline Age (years) & 25.12 & $19-39(3.75)$ & 25.69 & $19-35(3.91)$ & 24.96 & $19-39(3.71)$ & $\mathrm{MW}=1063.500, \mathrm{P}=0.311$ \\
\hline BMI $\left(\mathrm{Kg} / \mathrm{m}^{2}\right)$ & 20.69 & $18-25(1.64)$ & 20.15 & $18-23(1.5)$ & 21.10 & $18-25(1.5)$ & $\mathrm{MW}=805.000, \mathrm{P}=0.008^{*}$ \\
\hline
\end{tabular}

*Significant difference

\section{Serum lipid levels}

The mean serum lipid component levels for the entire study group and the two subgroups based on WHR are shown in Table 2.

Overall, the mean total cholesterol (TC) was $153.7 \mathrm{mg} / \mathrm{dL}$ (range 100-265 mg/dL; SD \pm 34.08 ) and the mean HDL and LDL levels were $45.5 \mathrm{mg} / \mathrm{dL}$ and $79.5 \mathrm{mg} / \mathrm{dL}$ respectively.

On comparing the serum lipid levels and lipid risk ratios between the group with WHR $>0.80$ and WHR $\leq 0.80$, no statistically significant difference was observed for any of the components (Table 2, Figure 1).

Table 2: Comparison of serum lipid levels and lipid risk factor ratios in subgroups according to WHR (WHR $>0.80$ versus $W H R \leq 0.80)$.

\begin{tabular}{|c|c|c|c|c|c|c|c|c|}
\hline \multirow{2}{*}{$\begin{array}{l}\text { Lipid } \\
\text { component } \\
\text { (mg/dL) } \\
\text { and lipid risk } \\
\text { factor ratios }\end{array}$} & \multicolumn{2}{|c|}{$\begin{array}{l}\text { Whole study group } \\
(\mathrm{N}=\mathbf{1 2 0})\end{array}$} & \multicolumn{2}{|c|}{$\begin{array}{l}\text { Subgroup WHR } \leq 0.80 \\
\left(\mathrm{n}_{1}=26\right)\end{array}$} & \multicolumn{2}{|c|}{$\begin{array}{l}\text { Subgroup WHR }>0.80 \\
\left(\mathrm{n}_{2}=94\right)\end{array}$} & \multicolumn{2}{|c|}{$\begin{array}{l}\text { Mann Whitney } \\
\text { U test for } \\
\text { comparison }\end{array}$} \\
\hline & Mean & Range (SD) & Mean & Range (SD) & Mean & Range (SD) & $\begin{array}{l}\text { Test value } \\
\text { (MW) }\end{array}$ & $\begin{array}{l}\text { P- } \\
\text { value }\end{array}$ \\
\hline HDL & 45.46 & $30-181(14.48)$ & 45.33 & $35-61(7.52)$ & 45.50 & $30-181$ (15.91) & 1121.000 & 0.519 \\
\hline LDL & 79.48 & $15-199(29.73)$ & 77.59 & $28-139(28.35)$ & 80.00 & $15-199(30.22)$ & 1178.000 & 0.779 \\
\hline VLDL & 30.94 & $11-250(29.90)$ & 32.44 & $16-250(45.20)$ & 30.52 & $11-180(24.37)$ & 1057.500 & 0.295 \\
\hline TG & 121.63 & $37-261(45.00)$ & 119.12 & $37-261(47.59)$ & 122.32 & $37-261(44.50)$ & 1128.500 & 0.551 \\
\hline $\mathrm{TC}$ & 153.74 & $100-265(34.08)$ & 151.12 & $109-218(28.89)$ & 154.47 & $100-265(35.49)$ & 1212.000 & 0.949 \\
\hline TG/LDL ratio & 1.73 & $0.4-6.8(1.07)$ & 1.71 & $0.45-5.1(1.05)$ & 1.74 & $0.4-6.8(1.08)$ & 1207.500 & 0.926 \\
\hline $\begin{array}{l}\text { Cholesterol/ } \\
\text { HDL ratio }\end{array}$ & 3.80 & $1.4-8.1(0.88)$ & $\begin{array}{l}3.90 \\
\pm 1.14\end{array}$ & $2.1-8.1(1.14)$ & 3.77 & $1.4-6.4(0.80)$ & 1201.000 & 0.893 \\
\hline
\end{tabular}

Correlation between WHR and serum lipid levels: The group was analyzed as a whole $(\mathrm{N}=120)$ for studying the correlation between lipid and WHR using Spearman's rank order correlation. The results are presented in Table 3, Figures 2 and Figure 3. The WHR showed a weak positive but statistically significant correlation with the serum VLDL levels (Spearman's rho $=0.198 ; \mathrm{P}=0.031$ ). No significant correlation was found with other lipid components or lipid risk ratios (Table 3).Additionally, the WHR strongly correlated with the BMI across the entire range of observations.

\section{Pregnancy complications}

The group of women with WHR $>0.80$ had an overall higher rate of developing complications in pregnancy [(10/94 (10.6\%) versus $2 / 26(7.7 \%)]$ as shown in Table 4. Five women in this group had missed abortion $(5.3 \%)$ compared to one woman in the group with WHR $\leq 0.80$.

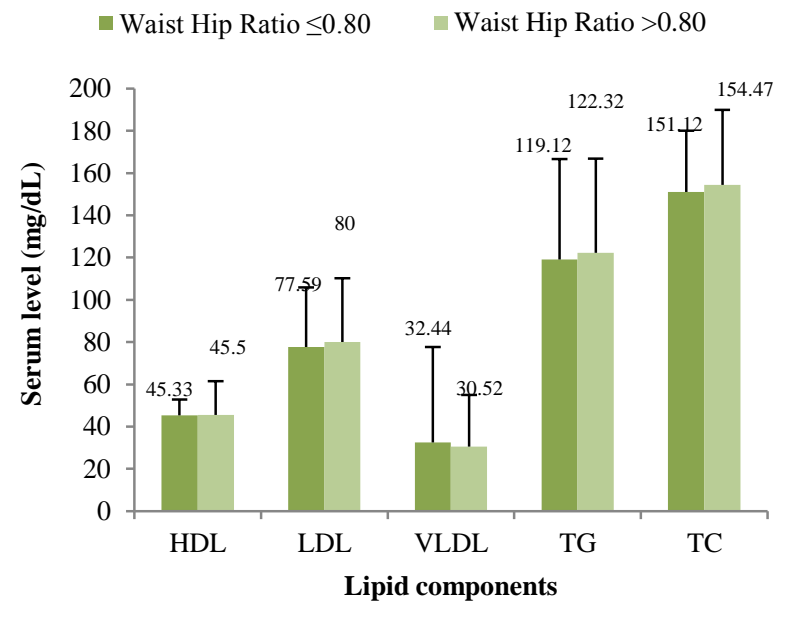

Figure 1: Serum lipid component levels among women with Waist Hip Ratio $\leq \mathbf{0 . 8 0}(\mathrm{n} 1=26)$ and women with Waist Hip Ration $>0.80$ (n2=94). 
Table 3: Correlation of Waist Hip Ratio with serum lipid component levels, lipid risk factor ratios and BMI $(\mathrm{N}=120)$.

\begin{tabular}{|c|c|c|}
\hline $\begin{array}{l}\text { Variable with } \\
\text { which } \\
\text { Correlation of } \\
\text { WHR } \\
\text { studied }\end{array}$ & $\begin{array}{l}\text { Correlation Coefficient } \\
\text { (Spearman's rho) }\end{array}$ & P-value \\
\hline HDL & $\begin{array}{l}0.003 \\
\text { No or negligible relationship }\end{array}$ & 0.971 \\
\hline LDL & $\begin{array}{l}0.073 \\
\text { No or negligible relationship }\end{array}$ & 0.430 \\
\hline VLDL & $\begin{array}{l}0.198 \\
\text { Weak positive relationship }\end{array}$ & $0.031 *$ \\
\hline TG & $\begin{array}{l}0.096 \\
\text { No or negligible relationship }\end{array}$ & 0.296 \\
\hline $\mathrm{TC}$ & $\begin{array}{l}0.043 \\
\text { No or negligible relationship }\end{array}$ & 0.642 \\
\hline TG/LDL ratio & $\begin{array}{l}0.005 \\
\text { No or negligible relationship }\end{array}$ & 0.960 \\
\hline $\begin{array}{l}\text { Cholesterol/ } \\
\text { HDL ratio }\end{array}$ & $\begin{array}{l}0.015 \\
\text { No or negligible relationship }\end{array}$ & 0.875 \\
\hline BMI & $\begin{array}{l}0.473 \\
\text { Strong positive relationship }\end{array}$ & $\begin{array}{l}0.000 * \\
(<0.001)\end{array}$ \\
\hline
\end{tabular}

*Significant correlation

Table 4: Pregnancy complications in the two subgroups according to WHR.

\begin{tabular}{|lll|}
\hline Antenatal Complications & $\begin{array}{l}\text { Subgroup } \\
\text { WHIR } \leq 0.80 \\
\left(\mathbf{n}_{1}=26\right)\end{array}$ & $\begin{array}{l}\text { Subgroup } \\
\text { WHIR>0.80 } \\
\left(\mathbf{n}_{2}=94\right)\end{array}$ \\
\hline Missed Abortion & $1(3.8 \%)$ & $5(5.3 \%)$ \\
\hline $\begin{array}{l}\text { Gestational Hypertension/ } \\
\text { Preeclampsia }\end{array}$ & 0 & $3(3.1 \%)$ \\
\hline $\begin{array}{l}\text { Gestational Diabetes } \\
\text { Mellitus }\end{array}$ & 0 & $1(1 \%)$ \\
\hline $\begin{array}{l}\text { Intrauterine Growth } \\
\text { Restriction }\end{array}$ & $1(3.8 \%)$ & 0 \\
\hline Vesicular Mole & 0 & $1(1 \%)$ \\
\hline $\begin{array}{l}\text { Total Antenatal } \\
\text { Complications }\end{array}$ & $2(7.7 \%)$ & $10(10.6 \%)$ \\
\hline $\begin{array}{l}\text { Number of newborns } \\
\text { admitted to NICU }\end{array}$ & 1 & 5 \\
\hline
\end{tabular}

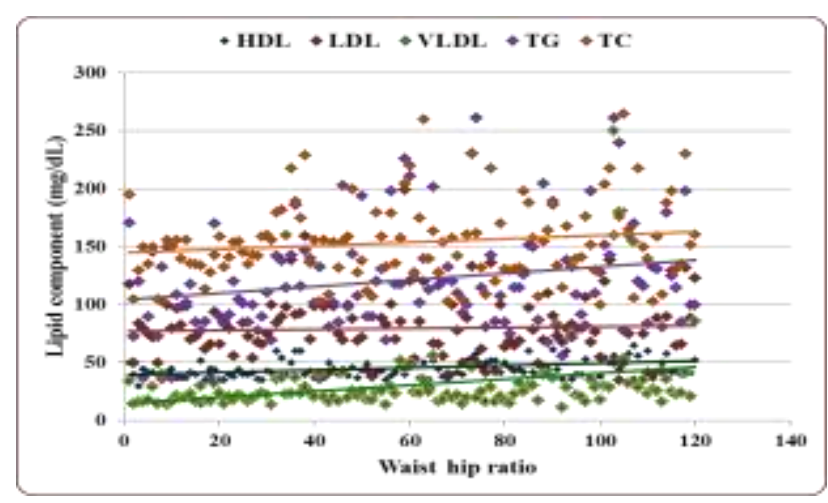

Figure 2: Correlation of waist hip ratio with serum levels of lipid components $(\mathrm{N}=120)$.

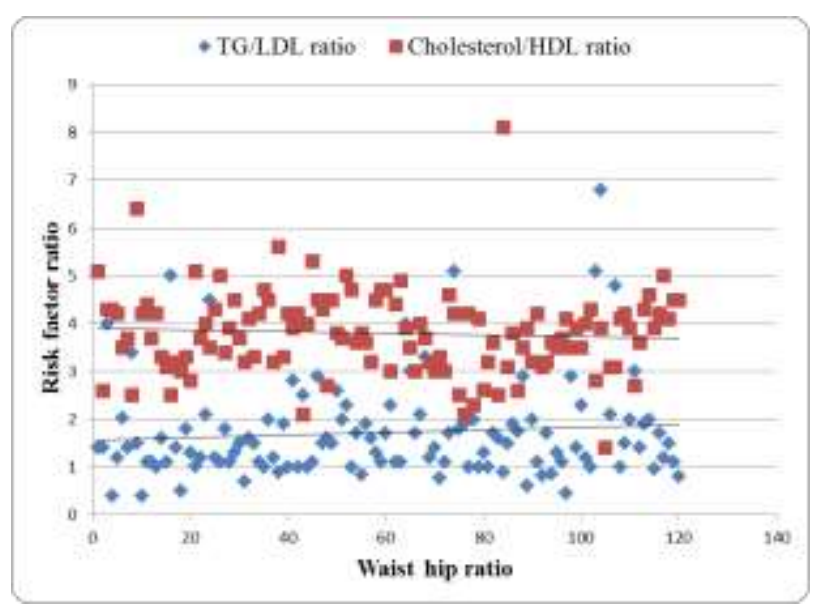

Figure 3: Correlation of waist hip ratio with lipid risk factor ratios.

Gestational hypertension and preeclampsia were also diagnosed in a higher proportion of women in this group. The babies born to mothers with WHR $>0.80$ had a higher rate $(5.3 \%)$ of admission to the Neonatal Intensive Care Unit (NICU).

\section{DISCUSSION}

In the present study, the WHR was found to correlate strongly with BMI across the whole range of observations, as has also been reported in earlier studies. The correlation of WHR with the serum VLDL levels was weakly positive and statistically significant. The other lipid components or the lipid risk ratios did not show significant correlation with WHR. Existent literature too suggests a variable correlation between the WHR and the various lipid component serum levels. ${ }^{2,3}$ A study by Seidell et al reported positive correlation of TG with WHR and a negative correlation with HDL. ${ }^{9}$ Further, in the present study, the mean serum lipid levels were found to be comparable among with women with normal WHR and those with WHR $>0.80$.

The absence of significant correlation with other lipid components could be due to the limited sample size included in the present analysis. The same may also explain the absence of difference between the lipid levels between the two subgroups based on WHR.

We found a higher rate of pregnancy complications among the women with high WHR compared to those with normal WHR. Overall, the gestational hypertension and missed abortions were higher in the high WHR subgroup of women. This is in agreement with the earlier studies that have found a higher incidence of hypertensive disorders of pregnancy among women with high WHR. ${ }^{5-8}$ Tabei et al measured the WHR in pregnancy upto 12 weeks of gestation and concluded that it could serve as a good predictor of preeclampsia. ${ }^{7}$ The study by Yamamoto et al found that WHR and BMI in early pregnancy were both related to the risk of developing preeclampsia. ${ }^{10}$ Similarly, Portelinha et al reported an association between obesity anthropometric 
markers (BMI and WHR) in women with a history of pre eclampsia. ${ }^{11}$ Significantly raised levels of VLDL were reported in patients who developed preeclampsia in a study by Kumari et al. ${ }^{12}$

Though in the present study, the WHR showed a strong positive correlation with the BMI, it is worth noting that mean BMI of the subgroup of women with WHR $>0.80$ (mean BMI $21.1 \mathrm{Kg} / \mathrm{m}^{2}$; range $18-25 \mathrm{Kg} / \mathrm{m}^{2}$; $\mathrm{SD} \pm 1.5$ ), was in the normal range for Indian population i.e. $<23 \mathrm{Kg} / \mathrm{m}^{2}$. It suggests that even though the body fat distribution is in the abnormal range (WHR >0.80; $\mathrm{n}_{2}=94$ ), only a small proportion of them are actually obese as per the BMI values. This also implies that if $\mathrm{BMI}$ is used as screening modality alone, many high-risk women with abnormal WHR will be missed. The large Indian study by Mishra et al also reported that high WHR may be metabolically detrimental even when the person is non-obese. ${ }^{2}$

Overall, the present study in context of the available literature supports the use of anthropometric screening of pregnant women in early pregnancy for predicting possible antenatal complications particularly gestational hypertension and preeclampsia. Identification of the most accurate measure or combination of measures remains a challenge.

\section{CONCLUSION}

The WHR in early pregnancy has the potential of being used as a clinical indicator or a surrogate marker for deranged lipid profile. It can also be used as a simple anthropometric screening in early pregnancy for identifying women at risk for developing hypertensive disorders of pregnancy. Well-designed cohort studies with large sample size may further establish the utility of this simple anthropometric ratio in preventing or predicting pregnancy complications.

\section{ACKNOWLEDGEMENT}

The authors would like to acknowledge Dr. Mita Mazumdar for the help and guidance extended during the course of the study.

Funding: No funding sources Conflict of interest: None declared

Ethical approval: The study was approved by the Institutional Ethics Committee

\section{REFERENCES}

1. Waist Circumference and waist- hip ratio: report of a WHO expert consultation, Geneva, 8-11 December 2008. World Health Organization. Geneva. 2011.

2. Mishra A, Pandey RM, Sinha S, Guleria R, Sridhar V, Dudeja V. Receiver operating characteristics curve analysis of body fat and body mass index in dyslipidaemic Asian Indians. Indian J Med Res. 2003;117:170-9.

3. Huxley R, Mendis S, Zheleznyakov E, Reddy S, Chan J. Body mass index, waist circumference and waist: hip ratio as predictors of cardiovascular risk- a review of literature. Eur J Clin Nutr. 2010;64:16-22.

4. Nahar N, Dubey S, Joshi A, Phadnis S, Sharma V. Association of anthropometric indices of obesity with diabetes, hypertension and dyslipidemia: a study from central India. Indian $\mathrm{J}$ Med Spec. 2012;3(1):6.

5. Sattar N. Antenatal waist circumference and hypertension risk. Obs and Gyne. 2001;97(2):268-71.

6. Salem W, Adler Al, Lee C, Smith GCS. Maternal waist to hip ratio is a risk factor for macrosomia. $\mathrm{Br} \mathrm{J}$ Obstet Gynaecol. 2011;119(3):291-7.

7. Taebi M, Sadat Z, Saberi F, Kalahroudi M. Early pregnancy waist-to-hip ratio and risk of preeclampsia: a prospective cohort study. Hypertension Research. 2014;38(1):80-3.

8. Kausar H, Dabhadkar S, Mehendale S, Kulkarni YS. Waist circumference, BMI, lipid profile between 616 weeks of pregnancy as predictors of Gestational hypertension and preeclampsia. Ind $\mathrm{J}$ App Res. 2013;3(2):274-6.

9. Seidell J, Cigolini M, Deslypere J, Charzewska J, Ellsinger B, Cruz A. Body fat distribution in relation to serum lipids and blood pressure in 38-year-old European men: the European fat distribution study. Atherosclerosis. 1991;86(2-3):251-60.

10. Yamamoto S, Douchi T, Yoshimitsu N, Nakae M, Nagata Y. Waist to hip circumference ratio as a significant predictor of preeclampsia, irrespective of overall adiposity. J Obs Gynae Research. 2001;27(1):27-31.

11. Portelinha A, Belo L, Cerdeira A, Braga J, Tejera E, Pinto $\mathrm{F}$ et al. Lipid levels including oxidized LDL in women with history of preeclampsia. Hypertens Pregnancy. 2010;29(1):93-100.

12. Kumari K, Singh U, Maharshi S, Singh R. Assessment of serum lipid profile in early pregnancy and its relation with pre eclampsia: a prospective study. Int J Reprod Contracept Obstet Gynecol. 2016;5(3):840-4.

Cite this article as: Khare D, Modi JN. Waist hip ratio in early pregnancy as a clinical indicator of serum lipid levels and predictor of pregnancy complications. Int J Reprod Contracept Obstet Gynecol 2016;5:1709-13. 